\title{
Accounting Policies, Management Judgements and Financial Reporting Quality of Small and Medium Enterprises In Nigeria: A Survey
}

\author{
Efeeloo Nangih*, Samuel Chikwuchehia Wali** \& Peggy Oluchi Anyanwu** \\ *Department of Accountancy, Chukwuemeka Odumegwu Ojukwu University, Igbariam \\ Anambra State, Nigeria. \\ **PhD Student, Ignatius Ajuru University of Education, Port Harcourt Rivers State, Nigeria \\ nangihlah@yahoo.co.uk, waliwalis@yahoo.com, peggyoluchi@gmail.com
}

\begin{abstract}
The accounting policy adopted by an enterprise, together with the level of approximations done by the management in financial statements, could either enhance or impair their relevance and reliability and, by extension, the credibility of financial decisions made by users of such reports. This is because financial statements portray the financial position and performance of entities. This study assesses the influence of management's choice of accounting policy and accounting approximations in financial statements on the quality of financial reports of Small and Medium Enterprises in Nigeria. The study was anchored on the Stakeholders' theory. The study also adopted the survey design approach. Data were mainly collected through the questionnaire and was analyzed using descriptive statistics and regression techniques. Findings revealed that wrong accounting policies and judgements might affect the quality of financial reports, together with other factors. It was recommended that small and medium enterprises management adhere to accounting standards when designing their accounting policies and in their judgements/approximations to reduce material errors and enhance the quality of their financial report.
\end{abstract}

Keywords: Accounting Policy, Management Judgements, Accounting Approximations, Financial Reporting Quality.

\section{How to Cite:}

Nangih, E., Wali, S. C., \& Anyanwu, P. O. (2021). Accounting policies, management judgements and financial reporting quality of small and medium enterprises in Nigeria: A survey. International Journal of Finance Research. 2(2). 58-70.

DOI. https://doi.org/10.47747/ijfr.v2i2.326.

\section{Introduction}

Financial statements are mainly stewardship reports prepared by management to all stakeholders to show the entity's financial status; in terms of performance, financial position, and changes in 
financial position (Nangih, 2018). They are agency reports; meant to serve as guidelines for the assessment of the entity by users. Akenbor \& Kiabel (2014) opined that the content of financial statements information influences the decision of stakeholders in their relationship with the business. For instance, it enables the creditors to assess the business's creditworthiness, helps the government know how much tax the business should pay, and provides a clue to the owners or investors on their returns on investment. They also serve as traffic signs, indicating the pathway along which the firm is navigating. An objective and reliable accounting information is a prerequisite for a proper decision-making process since they portray the entity's actual financial position and business performance as a particular date. Accordingly, all the numbers must be factual for financial reports to be relevant, reliable, understandable, and accurate. At the same time, the estimates and disclosures made by management must be reasonable, realistic and reliably based on the underlying accounting frameworks or standards. Accounting policies and management approximations are employed by management for transactions for which there are no precise means of measurement. They are usually employed in historical financial statements to measure the effects of past business transactions or the present status of an asset or liability. They are subjective and relative; therefore, prone to management bias.

A poor financial reporting quality occurs when the accounts is misstated and do not show and fair view of the entity's underlying records or economic events at any point in time. It arises when there are misstatements in the amounts, classifications, presentation, or disclosure of items in the financial statements against relevant accounting standards. Hence, the misrepresentations in financial reports are considered material when the user of a set of financial statements alters his economic decisions due to such misstatements (International Accounting Standards Board, (ISAB, 2010). Examples of poor quality financial statements, which may arise due to error or fraud include: 1. where an incorrect amount has been recognized (for example, an asset is not valued following the relevant IFRS requirement) 2 . an item is classified incorrectly (for example, the finance cost is included within the cost of sales in the statement of profit or loss or presentation is not appropriate) 3. the results of discontinued operations are not separately presented, 4. impairment loss not correctly estimated, 5. depreciation provision wrongly estimated, 6. inventory either overstated or deliberately understated, etc.

Though debatable, it is evident that accounting judgments and estimates are interlinked to the extent that both are highly subjective and significantly affect an entity's financials. It could be argued that the risk of misrepresentation of facts in financial reports could be caused mainly by the use of wrong management judgements and accounting policies, either intentionally or erroneously, by the preparers. Such may lead to the overstatement of income or the understatement of expenses in future periods. Galrat \& Winsley (2011), on their part, suggest that accounting estimates are management predictions of the monetary value of financial transactions and events whose measurement is uncertain. Accordingly, all accounting approximations, by the management, represented in financial statements should be measured by 
applying relevant international financial reporting standards to make it relevant, reliable, understandable, comparable, devoid of any material misstatements that can be deceptive and alter the views of the users. This is because even International Accounting Standards Board (IASB), like the International Financial Reporting Standards' standard-setter, admits that "to a large extent, financial reports are based on estimates, judgements and models rather than being exact depictions" (IASB, 2015). That shows that making approximations implies a certain level of subjectivity to the extent that two different estimates for an item can result in different results or effects on the financials. For this reason, the regulators (including auditors) have always emphasized the importance of disclosures regarding critical accounting approximations and managements' judgements done in the financials since they significantly affect the way profits are determined and users' perception by extension.

It is believed that the study will contribute to existing literature and also benefit a wide range of people- including the owners, accountants and managers of corporations, small and mediumsized businesses. It will also provide them with the proper knowledge to efficiently formulate the right accounting policies to manage their organizational resources. Again for researchers and students, it will serve as invaluable reference material for further research on related topics.

The following research questions were expected to be answered by the study:

to what extent do inventory policy and management's judgement on inventory valuation affect the faithful representation of financial reports? How much do depreciation policy and management's approximation of depreciation expenses in financial reports influence faithful representation? To what extent does amortization approximation and policy impact the faithful representation of financial reports? To what extent does impairment loss determination and approximations affect the faithful representation of financial reports?

Small and medium enterprises form a significant percentage of registered businesses in Nigeria. As such, they contribute significantly to the GDP of the country. The accounting policies, together with management judgements and approximations, particularly the SMEs, determine how transactions are measured, recognized and presented in financial statements. These form the bulk of transactions reported by an entity. Accordingly, management judgements and approximations arguably may impair or improve the faithful representation and relevance of financial information rendered by managers. Sagam (2006) asserts that even though management's estimation requires the involvement of competent staff using reliable and relevant data, there was a potential or likelihood of bias in the subjective criteria used in the estimates depending on what they want to achieve.

Given the prevalence of several management judgements in the measurement and recognition of items in financial statements, whether these opposing forces will result in an improved financial information quality or not is debatable and forms the most crucial issue to recent accounting researchers. Prior studies have tried to link accounting judgments and financial reporting quality 
in Nigeria, but the findings were inconsistent and highly controversial. Aside from that, the variables used were limited. For instance, Akenbor \& Kiabel (2014), Nnah (2017), Ayunku \& Eweke (2020), Nangih \& Anichebe (2021), etc., all tried to carry out studies related to the subject matter. However, we are not aware of any study examining the interconnectedness between accounting policies and management judgements (or approximations) and the quality of financial reports in Nigeria, particularly among SMEs. This study was meant to fill that gap and indicates our point of departure.

\section{Literature Review}

\subsection{Financial Reporting Quality and Measure}

Financial statements show the company's financial position and business performance (Nangih 2018). To ensure that the financial statements of an entity agree with financial reporting standards, directors are required to make reliable estimates, judgements and assumptions that affect the numbers reported in their financial reports. Since accounting judgements and approximations are subjective by nature, their results may not be the same; depending on who and the circumstances under which or the purpose for which such approximations are made. Misrepresentations and alterations in financial statements' quality arise where there is an inappropriate use of accounting policies, errors and material misstatements in financials, either deliberately or otherwise (Nangih \& Anichebe, 2021). It implies wrong estimates/judgements, which affects the faithful representation of the underlying numbers included in the financial statements. Simply put, such financial statements lack quality of relevance, faithful representation, understandability, and even comparability.

In this study, faithful representation was used to proxy financial reporting quality.

\section{Accounting Policies and Management Approximations}

Accounting policies are the specific principles, bases, conventions, rules, and practices applied or put in place by an entity to prepare and present financial statements (IASB 2010). Accounting standards set out the policies for financial statements and conditions to which they apply. On the other hand, management judgements are estimates or approximations made in financial statements usually based on historical evidence or information available to them and in line with certain accounting practices, bases, or methods. Accordingly, they are based on subjective and objective factors at the prerogative of the financial statement preparers.

Accounting standards represent an essential source of accounting estimates. IAS 8 Accounting Policies, Changes in Accounting Estimates and Errors states that a change in an accounting estimate is 'a change in the carrying amount of an asset or a liability, which emanate from the appraisal of the current status of, and expected future benefits and obligations associated with, assets and liabilities. Making accounting approximations, judgements and deciding accounting policy is a complex process that connotes obtaining all required information about the topic. This 
study discussed the following dimensions of accounting policies and management judgements: inventory approximation, depreciation approximation, amortization approximation and impairment approximations.

\section{Inventory policy and Approximation in the financial report}

International Accounting Standard 2-inventories deals with the scope, measurement, recognition, presentation and disclosures of inventories. It specifies that the nature of inventories. These may include; raw materials held for production, finished goods held for sale, work in progress (semifinished goods) or consumables (Bhattacharyya; 2011).

IAS 2 states that inventory should be measured at the lower costs and net realizable value. It specifies that management can choose between the First in First Out or weighted average cost methods when assigning costs to inventory (IASB 2010). This implies that management has alternatives and can estimate the value assigned to closing inventory using either of the methods specified in the standard (Nangih \& Anichebe 2021). Ultimately, the resultant effects will not be the same, depending on the method adopted, especially where deliberate manipulations occur. Usually, the method adopted, the cost formula applied, and the measurement criteria adopted by the entity; are indicated in the accounting policy.

\section{Depreciation Policy and Approximations}

The entity's depreciation policy shows the method of depreciation applied by the firm to prepare and present financial statements. By definition, depreciation is the systematic spread of the assets' depreciable amount over its estimated useful life (IASB 2010). It is an estimation of financial requirements since the only way to know how much an asset has depreciated is to value it periodically. Bhattacharyya (2011), maintains that depreciation provision is made to show that the entity recognizes the entire costs associated with a non-current asset over the entire period the firm will use it.

Most small businesses use the straight-line depreciation method, which assumes that an asset will depreciate by the same amount each year over a specific period (Bhattacharyya, 2011). Others use the reducing balance method of depreciation. However, both methods are based on management's judgements and approximations and will produce differing results on the entity's financial reports.

\section{Amortization Policy and Approximations}

The entity's amortization policy affects the amortization provisions made in the financial statements for intangible non-current assets. The policy usually shows the amortization applied by the firm in the preparation and presentation of financial statements. Amortization, by definition, is the systematic spread of the depreciable amount of intangibles non-current assets over its estimated useful life (Bhattacharyya; 2011). It is the spread of intangible non-current asset's depreciable amount over their estimated useful life. It is calculated to show that the entity 
recognizes the costs associated with intangible non-current assets over the entire period the firm will use them. IAS 38-Intangibles non-current assets provides two methods of systematically allocating the depreciable amount of intangibles: either based on the volume of sales or based on the number of units of production (Chukwu, 2006). However, both methods are based on estimates, which will, in turn, produce differing results.

\section{Impairment Policy and Approximations}

According to IAS 36 impairments, an asset is said to be impaired when the recoverable amount is less than its carrying amount. It means that the asset's carrying amount is greater than its recoverable amount as at statement of financial position date. According to the standard, an asset's recoverable amount is the higher of its fair value minus disposal costs and its value in use. It further specifies that the fair value is the price that would be received to sell an asset or paid to transfer a liability in an orderly transaction between market participants at the measurement date. In contrast, the value in use is defined as the present value of future cash flows from using an asset, including its eventual disposal.

Essentially, an entity must carry out an impairment review when evidence or an indication that impairment may have occurred. Chukwu (2006), stated that at the end of each reporting period, an entity should assess whether there is any indication that impairment might have occurred. If such an indication exists, the entity must estimate the asset's recoverable amount; which is the higher of the assets fair value less costs to sell and its value in use. The method of impairment loss determination, the event which led to the recognition of impairment, the amount of impairment loss, the discount rate used in the determination of the asset' in use, etc. must all be disclosed in the notes to the accounts as part of the entity's accounting policy.

\subsection{Theoretical Review}

This study was anchored on the Stakeholders' theory. The theory was propounded by Freeman (2004). Stakeholders have a stake or are connected to and are directly or indirectly connected to the entity. Bassey, Effiok \& Eton (2013) opined that stakeholders are groups or persons, which are influenced by the corporate activities or affect the entity either directly or indirectly". The success of any organization, in the long run, is dependent on the support and approval received from its stakeholders. Accordingly, the more influential the stakeholders are on the organization, the more the entity must adapt to their demands and needs to enjoy their support and patronage continually.

The basic assumption of the stakeholders' theory is that the firm's growth is a function of the successful management of its relationship with its stakeholders. It posits that the proper management of its stakeholders could affect the firm's performance. Therefore, the stakeholders' model advocates for an increased level of environmental awareness among business enterprises to the needs of its stakeholders. According to Freeman (2004), stakeholder theory begins with the notion that values are unavoidably part of business activity. In the day to day activity of a firm, 
there is a variety of stakeholders that relates to the firm besides the shareholders, including employees, customers, suppliers, governments, etc. According to Deegan (2004), the moral perspective of stakeholder theory is that all stakeholders have a right to be treated fairly by an organization, and managers should manage the organization for the benefit of all stakeholders, regardless of whether the stakeholder management leads to better financial performance. Therefore, the fundamental aspect of stakeholder theory is to identify the stakeholders an organization is accountable to, as these stakeholders are relevant if their investment is, in some form, subject to risk from the activities of the organization.

The relevance of the stakeholders to this study is that entities should be mindful of their needs and make conscious efforts to protect them at all times, as their actions and perceptions can affect the firm positively or negatively.

\section{Empirical Review}

There are limited empirical studies that assess the role of accounting policy and management judgements in enhancing financial reporting quality in Nigeria. However, several studies have examined the impact of information disclosures on financial statements quality. For instance, Nnah (2017) examined the impact of accounting estimates on the financial reporting quality of manufacturing companies in Nigeria. Employing the questionnaire as a source of data collection, which was tested by the multi-correlation analysis method, it was found that accounting estimates had a significant relationship with financial reporting quality.

Lugovsky \& Kuter (2020) investigated the effect of accounting policies and accounting estimates and their role in preparing fair financial statements in the digital economy. The study was carried out in Russia. The study used the exploratory research design and considered the main problems and limitations of the reliable preparation and presentation of reporting financial information. The study concluded that the degree of freedom provided by standard setters to preparers has a severe influence on the reporting data presented to the users. It also added that the reliability of financial reports is influenced by many other factors including but not limited to the choice of accounting, depreciation policies, the legality of the transaction and changes in accounting estimates.

Nangih \& Anichebe (2021) assessed the effects of accounting estimates on information misstatements of financial reports of Small and Medium Enterprises in Nigeria. Specifically, the study examined the impacts of depreciation estimates, impairment loss, inventory estimates, goodwill estimates and estimated useful life of assets on Financial reports. The population was Small and Medium Enterprises in Nigeria. The study employed the survey research design. Data were mainly collected primarily through the questionnaire and was analyzed descriptive statistics and regression technique via SPSS statistical software. Findings revealed that wrong estimates might lead to, but are not the only cause of misstatements in financial reports. 
Putri \& Suputra (2019) investigated the effect of disclosure of financial reports and managerial ability on earnings management in Indonesia from 2012 to 2016. Using a sample of 375 companies and audit quality as a moderating variable, the study - based on 33 voluntary disclosure items, found that disclosure of financial reports affects earnings management but had no significant effect on managerial ability.

Kanakriyah (2016) examined the impact of voluntary disclosure on the quality of accounting information according to users' perspectives in Jordan. Using the semi-structured interview conducted on 12 respondents drawn from 6 groups of accounting information users (financial managers, financial analysts, auditors, academics, creditors and investors), the paper found a strong effect of voluntary disclosure on the quality of accounting information. It was concluded that voluntary disclosure was vital in enhancing the economic decisions process.

Akenbor \& Kiabel (2014) investigated the relationship between accounting estimates and the financial reporting of hospitality companies in Nigeria. It was discovered that accounting estimates had a significant relationship with the credibility of financial reports.

Ahmed, Mohammed \& Adisa (2014) looked at the influence of provisions, a proxy for accounting estimates, in and earnings management in the banking industry. It was concluded that there was a positive relationship between provision for loan losses and earnings management.

Based on the research objectives, the following hypotheses were raised for the study:

$\mathbf{H O}_{1}$ : There is no significant relationship between inventory policy/approximation and faithful representation of financial reports

$\mathbf{H O}_{2}$ : There is no significant relationship between depreciation policy/approximation and faithful representation of financial reports

H03: There is no significant relationship between amortization policy/approximation and faithful representation of financial reports

H0 $_{4}$ : There is no significant relationship between impairment loss approximations and faithful representation of financial reports

\section{Research Method}

This study made use of the survey research design. In order to avoid accessibility difficulty, data was obtained employing purposive sampling technique from management staff (including finance and accounts staff) of some notable small and medium enterprises operating in Port Harcourt metropolis. The population is comprised of Small and Medium Enterprises located in Port Harcourt. In all, 125 respondents were selected, consisting of knowledgeable senior/management staff, accountants, auditors and tax consultants of some SMEs within the metropolis. This was considered the most relevant since data were sourced mainly from the questionnaire and other primary sources. The research instrument was subjected to vetting by 
experts in research and academics, whose suggested corrections were included in the final copy of the questionnaire administered to the respondents. The instrument's reliability was determined using the Cronbach's Alpha, which revealed coefficients of .645, .712, .635, .589 and .715 FFRP, INAP, DEAP, AMTA and IMPA sub-items, respectively. Data collected were analysed using the descriptive, correlation and regression techniques.

\subsection{Model Specification}

In a bid to capture the impact of accounting policies and management judgements/Approximation on financial reporting quality in financial reports of SMEs in Nigeria, we developed a functional relationship in line with the dependent (financial reporting quality) and independent variables (proxied by inventory policies/approximation, depreciation policy/approximation, amortization policy/approximation, and impairment loss approximation) as:

$\mathrm{FFRP}=\mathrm{f}($ INAP, DEAP, AMTA, IMPA).

This is further restated in a regression model thus:

FFRP $=a 0+a_{1} I N A P+a_{2}$ DEAP $+a_{3} A M T A+a_{4} I M P A+U_{t}$

Where FRPM= Faithful Representation, INAP= Inventory Policy and approximations, DEAP= Depreciation Policy and Approximations, AMTA= Amortization Policy and Approximations, $\mathrm{IMPA}=$ Impairment Loss and Approximations and $\mathrm{U}=$ Error Term

\section{Findings and Discussions}

\subsection{Test of Hypotheses}

The results of the test of hypotheses were presented in table 2 below:

Table 1: Correlations

\begin{tabular}{|ll|r|r|r|r|r|}
\hline & \multicolumn{1}{|c|}{ INAP } & DEAP & META & IMPA & \multicolumn{1}{c|}{ FFRP } \\
\hline INAP & Pearson Correlation & 1 & $.247^{* * *}$ & $-.194^{*}$ & -.045 & $.394^{* * *}$ \\
& Sig. (2-tailed) & & .006 & .030 & .619 & .000 \\
& $\mathrm{~N}$ & 125 & 125 & 125 & 125 & 125 \\
\hline DEAP & Pearson Correlation & $.247^{* * *}$ & 1 & $-.191^{*}$ & $.276^{* * *}$ & -.069 \\
& Sig. (2-tailed) & .006 & & .033 & .002 & .447 \\
& $\mathrm{~N}$ & 125 & 125 & 125 & 125 & 125 \\
\hline META & Pearson Correlation & $-.194^{*}$ & $-.191^{* *}$ & 1 & $-.243^{* *}$ & -.012 \\
& Sig. (2-tailed) & .030 & .033 & & .006 & .896 \\
& $\mathrm{~N}$ & 125 & 125 & 125 & 125 & 125 \\
\hline IMPA & Pearson Correlation & -.045 & $.276^{* * *}$ & $-.243^{* *}$ & 1 & .139 \\
& Sig. (2-tailed) & .619 & .002 & .006 & 123 \\
& $\mathrm{~N}$ & 125 & 125 & 125 & 125 & 125 \\
\hline FFRP & Pearson Correlation & $.394^{* * *}$ & -.069 & -.012 & .139 & 1
\end{tabular}




\begin{tabular}{|l|r|r|r|r|r|} 
Sig. (2-tailed) & .000 & .447 & .896 & .123 & \\
$\mathrm{~N}$ & 125 & 125 & 125 & 125 & 125 \\
\hline
\end{tabular}

**. Correlation is significant at the 0.01 level (2-tailed).

*. Correlation is significant at the 0.05 level (2-tailed).

Source: Researcher's Computation using SPSS 23

Table 2: Regression Result Summary

\begin{tabular}{|c|c|c|c|c|c|c|}
\hline \multirow{2}{*}{\multicolumn{2}{|c|}{ Model }} & \multicolumn{2}{|c|}{ Unstandardized Coefficients } & \multirow{2}{*}{$\begin{array}{c}\text { Standardized } \\
\text { Coefficients }\end{array}$} & \multirow[b]{2}{*}{$\mathrm{T}$} & \multirow[b]{2}{*}{ Sig. } \\
\hline & & $\mathrm{B}$ & Std. Error & & & \\
\hline \multirow[t]{6}{*}{1} & (Constant) & -.316 & .908 & & -.348 & .728 \\
\hline & INAP & .695 & .121 & .483 & 5.741 & .000 \\
\hline & DEAP & -.290 & .105 & -.238 & -2.760 & .007 \\
\hline & AMTA & .136 & .118 & .097 & 1.153 & .251 \\
\hline & IMPA & .418 & .144 & .249 & 2.914 & .004 \\
\hline & $\mathrm{R}=.490$ & $\mathrm{R}^{2}=.240$ & $\begin{array}{l}\text { Adjusted } \mathrm{R}^{2}= \\
.215\end{array}$ & $\mathrm{~F}=9.488$ & Sig. $=.000$ & \\
\hline
\end{tabular}

a. Dependent Variable: FFRP

Source: Researcher's Computation using SPSS 23

\subsection{Discussion of Findings}

The results in table 1 show that the Pearson Correlation results indicate positive correlations between INAP and IMPA and FFRP, while AMTA and DEAP are negatively correlated with FFRP. However, only INAP is significantly correlated with FFRP. This suggests that inventory policy/approximation and the firms' impairment policy/approximations likely increase financial reporting quality. Table 2 , the $\mathrm{R}$ statistic of .490 , indicates that the independent variables have weak joint positive correlations with FFRP. The adjusted $\mathrm{R}^{2}$ statistics of .215 reveals that the independent variables explain only $21.5 \%$ of the variations in the dependent variable. Thus, accounting policies and approximations do not purely account for the quality of financial reports. The F statistic of 4.88 , which is significant at the $1 \%$ level, indicates that the model has a good fit.

Furthermore, the results of the t-statistics reveal that all the independent variables have positive relationships with financial reporting quality except INAP, which are equally significant except AMTA. The INAP of 5.741, which is significant at $1 \%$, indicates that financial reporting quality is likely to increase as inventory approximation increases.

The negative relationship between depreciation approximation policy and financial reporting quality. In the case of DEAP, it is also found to be negative and significant at a $1 \%$ level of significance. This implies that depreciation approximations/policies are unlikely to cause 
misstatement in financial reports of SMEs in Nigeria, which is because the basis for such approximations and management judgements are more realistic and can be more likely ascertained.

More so, the t-statistic of 1.15 and associated p-value of .251 for AMTA is also an indication that amortization of intangible non-current assets approximations can increase financial reporting quality of faithful representation, but it is not significant. The coefficient of .136 also shows that it can only constitute a small proportion of financial reporting quality. This is also supported by the correlation results, which shows a negative correlation with FFRP. This negates the findings of Nnah (2017). The reason is that, like depreciation approximations, the basis for its estimation is more realistic and accurate. However, its positive relationship with a faithful representation of financial reports is because amortization values may not reflect the actual fall in the value of intangible non-current assets in real terms.

Lastly, the regression result also established that impairment approximation due to management judgment has a high positive effect on faithful representation of financial statements, given the coefficient of .418 and t-statistic of 2.91, which is also significant at $1 \%$. This was consistent with the findings of Akenbor \& Kiabel (2014). The reason for this is that impairment loss is also tough to estimate, and thus, likely to increase the misstatements in the quality of financial reports of SMEs in Nigeria. The table above can explain as much as $41.8 \%$ of variations in financial misstatements, which calls from a more realistic basis of approximations.

\section{Conclusion}

The study examined the influence of accounting policies and management judgements on the quality of financial statements of small and medium enterprises in Nigeria. The results indicate positive correlations between inventory estimates or approximations, impairment policies/estimates, and financial reporting quality. In contrast, depreciation and amortization approximations are negatively correlated with a faithful representation of financial reports. Thus, accounting policy and management judgements do not only account for financial statement quality but other variables. Furthermore, the results of the t-statistics revealed that all the independent variables have positive relationships with financial reporting quality except inventory policy/approximations. Lastly, the regression result also established that impairment loss approximation has a high positive effect on the faithful representation or financial reporting quality, given the coefficient of .418 and t-statistic of 2.91 , which is also significant at $1 \%$. The study concludes that the use of accounting policies and management judgements, though contribute significantly to but are not the only factors responsible for SMEs' poor quality of financial reports. Therefore, the study recommends that management be cautious and follow the provisions of relevant accounting standards (usually the International Financial Reporting 
Standards) when formulating accounting policies and making accounting judgements or approximations not to present a misleading financial report. It was also recommended that management ensure strict compliance to relevant accounting standards to ensure their financial statements are of high quality.

\section{REFERENCES}

Ahmed, A.; Mohammed, A.Y. \& Adisa A.O (2014) Loan loss provision and earnings management in Nigerian money deposit banks. Mediterranean Journal of Social Sciences, 5(17);49

Akenbor, C.O., \& Kiabel B.D. (2014), Accounting estimates and credibility of financial statement in the hospitality industry in Nigeria; Mustang Journal of Accounting and Finance, 9 (6) 98-107.

Ayunku, P.E \& Eweke G.O. (2019). Accounting estimates and financial reporting quality: evidence from quoted deposit money banks in Nigeria. Federal University of Otuoke Journal of Management Sciences, 3 (1) 41-51.

Bhattacharyya, A.K. (2011). Financial accounting and reporting; a practical guide. Second Edition. PHI Learning, Private Limited, New Delhi-110001

Bassey, B. E., Effiok, S. O \& Eton, O. E. (2013). The impact of environmental accounting and reporting on organizational performance of selected oil and gas companies in Niger Delta Region of Nigeria. Research Journal of Finance and Accounting, 4(3), 57-73

Chukwu, G.J. (2006). Accounting Standards; an illustrative approach to SASs, IASs and IFRSs. Ano Publishing Company, Port Harcourt.

Deegan, C. (2004). Environmental Disclosures and Share Prices - A Discussion about the Efforts to Study this Relationship, Accounting Forum, 28, 87-97.

Galrat, A.W \& Winsley, J.R (2001). Managerial accounting estimates in corporate reportingevidence from American companies; Quarterly Review of Accounting and Finance, 13 (1), 103-117.

Freeman, R.E. (2004) The Stakeholder Approach Revisited. Zeitschrift für Wirtschafts-und Unternehmensethik, 5, 228-241

IASB (2010). The conceptual framework for financial reporting. Exposure Draft ED/2010/1IFRS Foundation

IASB (2015) The Conceptual Framework for Financial Reporting. Exposure Draft ED/2015/3. IFRS Foundation 
Kanakriyah, R. (2016). Voluntary disclosure and its effect on the quality of accounting information according to users' perspective in Jordan. American Journal of Business, Economics and Management,4(6):134-146

Lugovsky, D. \& Kuter, M. (2020). Accounting policies, accounting estimates and its role in the preparation of fair financial statements in digital economy. Springer Nature Switzerland.

Nangih, E. \& Anichebe, A.S. (2021). Accounting estimates and misstatements in financial reports in Nigeria: A Survey of Small and Medium Enterprises. Journal of Accounting and Financial Management 7 (3), 50-59.

Nangih, E (2018). Nexus between creative accounting practices and financial statements quality in Nigeria: a reflection of oil servicing companies in Port Harcourt metropolis. Journal of Accounting and Financial Management. 3 (4), 16-23

Nnah, G.N (2017). Accounting estimates and financial reporting quality of quoted manufacturing companies in Nigeria. PhD Accounting theses presented to the Postgraduate School of Rivers State University, Port Harcourt, November 2017.

Sagam, J.P (2006). Fair value accounting and accounting estimates in financial estimates. Journal of Investment and Public Policy, 14 (1), 82-99.

Putri, L. \& Suputra, I. (2019). The effect of disclosure of financial report and managerial ability on earnings management with audit quality as a moderating variable. Research Journal of Finance and Accounting, 10 (2), 33-39.

\section{Copyrights}

Copyright for this article is retained by the author(s), with first publication rights granted to the journal.

This is an open-access article distributed under the terms and conditions of the Creative Commons Attribution license (http://creativecommons.org/licenses/by/4.0/) 